\title{
A legalização da cannabis no Uruguai - uma mudança paradigmática na política de drogas?
}

\author{
Cannabis legalization in Uruguay - a paradigm change in drug \\ policy?
}

\section{Thomas Kestler}

\section{Resumo}

O Uruguai se tornou o primeiro país a legalizar, em 2013, a produção e a comercialização de produtos derivados da cannabis. Esse passo significou não apenas um distanciamento em relaçáo à estratégia nacional de política de drogas vigente há muitos anos, mas também um distanciamento frente às diretrizes para a política de combate às drogas definida em tratados internacionais. Em consequência disso, fala-se frequentemente em uma mudança de paradigmas na política de drogas uruguaia. O presente artigo busca elucidar em que medida essa concepção é adequada e se, de fato, é possível falar de mudança paradigmática no sentido oferecido pelo teórico da ciência Thomas Kuhn. O artigo evidencia que a política de legalização da cannabis no Uruguai, ainda que apresente uma mudança notável nos rumos da política anterior, não é ampla o suficiente para que se possa falar de fato de uma mudança paradigmática na política de drogas.

\section{Palavras-chave}

Política de Drogas; Uruguai; Mudança Política; Paradigmas de Políticas Públicas.

\begin{abstract}
Uruguay became the first country to legalize, in 2013, the production and comercialization of products derived from cannabis. This step meant not only a departure from the national drug policy strategy in place for many years, but also a departure from the guidelines for drug policy defined in international treaties. This kind of change, some people say, may represent, a paradigm shift in Uruguayan drug policy. This article seeks to clarify the extent to which this conception is accurate and whether, in fact, it is possible to classify that measure as a paradigmatic change in the sense offered by science theorist Thomas Kuhn. The article shows that the cannabis legalization policy in Uruguay, although it presents a notable change in the direction of the previous policy, it is not broad enough to talk about a paradigm shift in drug policy.
\end{abstract}

\section{Keywords}

Drug Policy; Uruguay; Political Change; Policy Paradigms. 


\section{Introdução ${ }^{1}$}

Dentre as inovaçôes políticas mais notáveis dos últimos anos na América Latina está certamente a legalização da cannabis no Uruguai em dezembro de 2013, que fez com que o país se tornasse pioneiro na política de drogas e também viesse a ser um caso experimental importante para a comunidade internacional. A experiência levaria o Uruguai a ser o primeiro país no mundo a incluir todas as etapas do mercado da cannabis, desde a produção até a distribuição, em seu quadro legal. O governo de centro-esquerda de José Mujica justificou esse passo com o argumento de que, sob o risco de perder a guerra contra as drogas, seria necessário levar adiante novas abordagens na política de drogas. "Alguém precisa dar esse primeiro passo", afirmou Mujica diante dos críticos dessa iniciativa ${ }^{2}$.

A decisão que levaria a esse passo foi resultado de um processo de aprendizagem de longo prazo que, ao final, levaria ao abandono de uma prática de longa data de criminalização do consumo da cannabis, culminando também em um distanciamento das diretrizes, definidas em tratados internacionais, em relaçáo à temática das drogas. Diante dessa evolução, tanto pessoas envolvidas no processo quanto observadores têm dito frequentemente tratar-se de uma mudança paradigmática (p.ex. GARAT, 2015, p. 50). A utilizaçáo desse conceito - em parte de maneira inflacionada - parece ser de fato justificada nesse caso em específico, uma vez que a legalização da cannabis baseouse em uma compreensáo radicalmente nova da ideia de consumo de drogas bem como em uma perspectiva diferente frente aos seus consumidores. Estes últimos passaram a ser vistos como cidadáos e cidadâs comuns, em vez de delinquentes ou pessoas marginalizadas socialmente - ou seja, pessoas usufruindo de seu direito constitucional à autodeterminação. Casos de consumo excessivo passaram a ser vistos como questóes sociais e de saúde, e não mais como delitos previstos no código penal.

O teórico da ciência Thomas Kuhn cunhou e popularizou o conceito de paradigma científico em sua obra clássica "The Structure of Scientific Revolutions" (2009 [1962]). Ele o compreendia como um conjunto de pressupostos fundamentais, amplamente aceitos - mais especificamente, cosmovisóes científicas, a partir das quais seriam derivadas questóes de pesquisa concretas, preceitos e normas científicas. Os paradigmas serviriam também para legitimar um campo científico, oferecendo algo

\footnotetext{
${ }^{1}$ Texto traduzido do alemão por Anelise F. P. Gondar, com recursos do Centro de Estudos Europeus e Alemães - CDEA/ UFRGS-PUCRS (https://cdea.tche.br/site/).

${ }^{2}$ Entrevista dada ao jornal $O$ Globo, 20/06/2012. Disponível em: <http://oglobo.globo.com/mundo/ alguemtemqueserprimeirodizpresidentejosemujica5271888>. Acesso em: 6. nov. 2016.
} 
como um consenso fundamental no âmbito disciplinar que apenas raramente, em condiçóes extraordinárias, seria questionado ou revisto. Peter Hall (1989; 1993) transfere esse conceito para o contexto político considerando o Estado como um ator político decisivo com açóes igualmente orientadas por pressupostos paradigmáticos. Analogamente ao que Kuhn propóe, ele compreende uma mudança paradigmática como um processo de aprendizagem em múltiplos níveis, no curso do qual paulatinamente todos os níveis de um sistema de conviç̧óes políticas vão se transformando: "[T]he overarching goals that guide policy in a particular field, the techniques or policy instruments used to attain those goals, and the precise settings of these instruments" (HALL, 1993, p. 278). Dessa forma, mudanças políticas radicais teriam origem não em pressóes sociais primordialmente ou em disputas de interesses na arena pública, como se presume em concepçóes pluralistas do processo político, mas derivariam de processos de aprendizagem, que ocorrem em grande medida de forma isolada na esfera estatal.

Esse pressuposto também se confirmaria no caso da política de drogas uruguaia? Corresponderia essa mudança paradigmática ao padrão que Hall descrevera com base na política econômica do Reino Unido? No presente artigo, essa questão será discutida com o objetivo de iluminar o papel das ideias e dos processos de aprendizagem na política contribuindo assim para o avanço de abordagens baseadas nas ideias da pesquisa sobre políticas públicas [policy] sob a ótica neoinstitucional. ${ }^{3}$ Inicialmente será apresentada a ideia de paradigma de políticas públicas [policy-paradigm] e da aprendizagem da política segundo Hall. Em seguida, será objeto deste estudo o desenvolvimento da política de drogas no Uruguai e, por fim, levar-se-á em consideração o regime de controle de drogas no contexto internacional. Uma mudança paradigmática no âmbito da política de drogas só pode ser tida como realizada quando se encontra também refletida no discurso internacional e, por fim, encontra expressáo em diretrizes internacionais.

\section{Social learning e policy-paradigms segundo Peter Hall}

O artigo de Peter Hall (1993) sobre transformação política no Reino Unido é, em vários sentidos, representativo para uma mudança de perspectiva na Ciência Política. Por um lado, ele dá continuidade a uma virada institucionalista, que tem

\footnotetext{
${ }^{3}$ Para um panorama acerca de abordagens baseadas em ideias no contexto da pesquisa em políticas públicas, ver Daniel Beland (2016).
} 
início nos anos de 1980 sob o slogan "bringing the state back in" (EVANS; RUESCHEMEYER; SKOCPOL, 1985). Com isso, teve início uma revisão das estruturas e instituições: após um período debruçando-se sobre atores e preferências, passou-se a vislumbrar cada vez mais as estruturas e instituiçóes como fatores influenciadores independentes. Por outro lado, o artigo de Hall marca o início da chamada virada ideacional (ideational turn), que consistiu em integrar as ideias à teoria das instituiçôes, considerando-as como fator decisivo para estabilidade e mudança (BLYTH, 2003). Na contribuição de Hall, as ideias são tidas como modelos explicativos coerentes e amplos - paradigmas de políticas públicas - a partir dos quais podem ser deduzidos não apenas instrumentos políticos concretos e medidas, mas também a própria "natureza dos problemas a serem resolvidos" (HALL, 1993, p. 279). No âmbito da política econômica, trata-se, sobretudo, do keynesianismo e do monetarismo que, na análise da política econômica do Reino Unido feita por Hall, se apresentavam como paradigmas opostos. Estes paradigmas caracterizam-se pelo fato de normalmente não serem questionados e instruirem a ação política sobretudo em áreas políticas complexas e situaçóes de insegurança. Analogamente ao conceito de Kuhn de "normal science", Hall descreve decisóes políticas diárias como "highly routinized, in that the range of options [... is] generally restricted by the conventions of the reigning paradigm” (Idem, p. 281). Nesse estágio, as decisóes políticas estão nas mãos de funcionários ministeriais; atores políticos e a esfera pública participam, na melhor das hipóteses, apenas marginalmente. Apenas em situaçôes de crise, nas quais as formas usuais de condução da política se mostram insuficientes, dá-se uma mudança ampla também ao nível dos instrumentos políticos. Mesmo uma mudança de segunda ordem [second order change], nas palavras de Hall, é uma mudança que ocorre no interior de um paradigma vigente.

Uma mudança teria ocorrido apenas em caso de fracassos contínuos, de tentativas de correção de rota sem sucesso e de um acúmulo de 'anomalias' - resultados políticos contrários aos pressupostos em vigor e que, por conta disso, teriam exigido uma revisão radical do respectivo arcabouço jurídico. No caso da política econômica do Reino Unido, tal anomalia residiu no aumento simultâneo da inflaçáo e do desemprego nos anos de 1970, o que contradizia os pressupostos do keynesianismo baseados na Curva de Phillips. Na fase de reorientação, o locus do fazer político se transfere dos aparatos ministeriais para o governo e o parlamento. A esfera pública também participa cada vez mais do debate em torno de possíveis soluçôes, grupos de jornalistas e especialistas disputam a prerrogativa da interpretaçáo mais adequada dos 
fatos ${ }^{4}$. Hall fala de um mercado das ideias em expansão, que também teria abrangido a arena eleitoral no Reino Unido (p. 286). O discurso da política econômica pendeu cada vez mais em favor de uma nova abordagem, a do monetarismo, que prometia uma solução simples e convincente para as contradiçóes ainda existentes. Isso também mostra que a permanência de um paradigma também depende da existência de alternativas a ele (BÉLAND, 2005). Abordagens políticas insuficientes são frequentemente apenas levadas adiante porque esquemas alternativos não são imagináveis ou porque falta um modelo explicativo amplo que possa justificar as mudanças políticas.

Por fim, há, além de tudo, mais um fator. Ainda que Hall enfatizasse com veemência o aspecto da aprendizagem política, esse conceito demonstrou ser limitado. Os atores, em geral, não estão prontos para renunciar ao cerne das suas convicçóes, mesmo quando confrontados com claras anomalias. Por isso, uma mudança política definitiva está intimamente relacionada ao fator 'poder'. Tão somente quanto as relaçóes de poder se deslocam, como no caso da eleição de Margaret Thatcher em 1979, e os detentores de uma nova ideia ocupam posições decisivas é que há a possibilidade de uma ruptura em direção a um modelo alterativo. $\mathrm{O}$ último estágio da mudança política se realiza quando da institucionalização do novo paradigma através de uma substituição de pessoal nas respectivas instituiçôes e ministérios. Dessa forma, o caso descrito por Hall evidencia que processos de aprendizagem no fazer político têm limites e, no final das contas, a distribuiçáo de poder, não o poder de convencimento de uma ideia, decidirá quais concepções políticas prevalecerão.

Em que medida essa concepção é adequada à análise e à explicação da mudança política de forma geral? Os pressupostos de Hall acerca do significado e qualidade dos paradigmas foram criticados a partir de várias perspectivas (CARSTENSEN, 2015). Entre outras coisas, uma questão debatida foi em que medida o exemplo da política econômica no Reino Unido poderia ser aplicado a outros contextos políticos e áreas de política pública. De fato parece difícil identificar evoluções semelhantes, nas quais um amplo paradigma de política pública tenha sido completamente substituído por outro. Teria o estudo de Hall apresentado uma excepcionalidade, que náo poderia ser considerada um caso típico para uma mudança política? Ou seriam as mudanças paradigmáticas simplesmente muito raras e, por isso, não observáveis de forma mais

4 É possível falar aqui, nos termos de Maarten Hajer (1993), de coligaçóes discursivas concorrentes. 
frequente conforme o caso descrito por Hall? É possível que o caso da mudança na política de drogas uruguaia, que como poucos parece ser similar ao caso apresentado por Hall, possa fornecer pistas acerca da própria capacidade de generalização do conceito $^{5}$. A ideia de mudança paradigmática poderá servir, nesse sentido, para descrever a experiência das evoluçôes recentes no Uruguai e no contexto regional em que o país está inserido. É possível observar, em termos de políticas de drogas, paradigmas similares ao da política econômica do Reino Unido? A mudança política foi levada a cabo com base também em anomalias, processos de aprendizagem e ligada à ampliação sucessiva da esfera discursiva? Qual o papel do fator 'poder' na tomada de decisão relacionada a uma nova abordagem na política de drogas?

\section{O caminho até a legalização da cannabis no Uruguai}

Por muito tempo, a política de drogas uruguaia se orientou, como nos demais países da regiáo, pelas diretrizes internacionais ancoradas em diversos tratados, sobretudo na Convenção Única sobre Entorpecentes de 1961 (Single Convention on Narcotic Drugs) das Naçóes Unidas que gerou a base para o controle de drogas em nível global e também serviu de plataforma para diversos marcos regulatórios sobre drogas em vários países. Ainda que os tratados tenham objetivado sobretudo o combate ao tráfico de drogas, é possível reconhecer claramente as tendências proibicionistas que abarcavam o consumo de drogas e que formavam o consenso básico acerca da política internacional de drogas. No artigo 4 lê-se, p. ex., que:

The parties shall take such legislative and administrative measures as may be necessary [...] to limit exclusively to medical and scientific purposes the production, manufacture, export, import, distribution of, trade in, use and possession of drugs (UNODC 2013, p. 30).

A Convenção também continha uma classificação de entorpecentes com base em seu potencial aditivo e no grau de prejuízo à saúde e nela a cannabis ocupava a mesma - e mais alta - categoria de risco que a heroína e a cocaína (BEWLEY-TAYLOR; BLICKMAN; JELSMA, 2014).

Em nível regional, o Acordo Sul-Americano sobre Entorpecentes e Psicotrópicos (Acuerdo Sudamericano sobre Estupefacientes y Psicotrópicos, ASEP)

\footnotetext{
${ }^{5} \mathrm{Um}$ dos atores essenciais na política de drogas no Uruguai baseou-se diretamente sobre o conceito de mudança de paradigma segundo Thomas Kuhn (GARAT, 2015, p. 67).
} 
assinado em 1973 formaria a base para a legislaçáo de drogas uruguaia de 1974 e sua tendência repressiva. Essa lei constituiu uma exceção na regiáo uma vez que retirava $o$ consumo e o cultivo de cannabis para consumo próprio do rol de atividades proibidas (GARAT, 2015). Na prática policial e jurídica, no entanto, praticamente não havia distinção entre consumidores e traficantes. Como a legislação sobre drogas dava margem a que o juíz definisse a seu critério a quantidade de cannabis pertinente ao consumo próprio a cada julgamento, isso fazia com que mesmo os que eram apenas consumidores fossem perseguidos pela justiça. De acordo com um estudo, a maioria das detençóes entre os anos de 2006 e 2009 ocorreu por posse de cannabis - em quase metade dos casos, as quantidades eram menores que dez gramas (GARIBOTTO, 2010, p. 85-86). Pode-se interpretar essa prática como uma expressão de uma atitude paternalista e repressiva em relação a drogas que também se refletia na opinião pública ${ }^{6}$. Usuários de drogas eram tidos como antissociais, irresponsáveis e incapazes de exercer o autocontrole, razáo pela qual seria necessário ao Estado intervir de maneira corretiva - fosse pela sanção penal ou por caminhos terapêuticos. Em outras palavras: A autonomia individual não tinha precedência no caso do uso de drogas, uma vez que usuários de drogas eram tidos como incapazes de exercê-la - independentemente da quantidade e tipo de droga consumida (SANJURJO GARCÍA, 2013).

No entanto, desde os anos 2000 aproximadamente, pôde-se comprovar cada vez mais um movimento contrário a esse - assim chamado - paradigma de política de drogas. Em 2001, o presidente Jorge Batlle do Partido Colorado chegou a falar abertamente acerca da necessidade da legalização das drogas. Ele se baseava em economistas liberais como Milton Friedman e Gary Becker, os quais previam a liberalização como caminho para baixar o preço das drogas fazendo assim com que a oferta também fosse reduzida. $\mathrm{O}$ apoio a essa virada política também foi sinalizado por membros da Suprema Corte de Justiça uruguaia e da Junta Nacional de Drogas (JND), uma agência fundada em 1988 e responsável pela coordenação, supervisão e avaliação da política de drogas (GARAT, 2015). Seus posicionamentos públicos indicavam estar em curso um processo de aprendizagem no âmbito estatal, sobretudo no interior da JND, que até então havia sido responsável por uma política de drogas proibicionista e

\footnotetext{
6 “60\% of Uruguayans Oppose Marijuana Legalization”, InSight Crime, 19.7.2012, Disponível em: <http:/www.insightcrime.org/news-briefs/60-of-uruguayans-oppose-marijuana-legalization>. Acesso em: 15. nov. 2016.
} 
que, sob a direção de Julio Calzada, um defensor de abordagens liberais, acabaria por se tornar de fato a instituição impulsionadora da reforma.

Contudo, o debate não se limitou de forma alguma apenas a atores no âmbito do Estado. No nível internacional, redes e grupos de ativistas em defesa da legalização da cannabis também ofereciam aos ativistas uruguaios uma plataforma para troca de informaçôes (HOFFMANN, 2016). No ano de 2005 foi realizado pela primeira vez, a partir do exemplo do Global Marijuana Marches ${ }^{7}$, um Smoke-In em Montevidéu no qual cerca de 300 participantes exigiriam a liberação da cannabis e o fim da estigmatização de seus consumidores. A polícia não interveio, uma vez que havia recebido a orientação de respeitar o consumo (permitido legalmente) e a liberdade de expressão (CASTRO, 2014). Encorajados com essa experiência, ativistas organizaram no ano de 2006 mais uma manifestação que daria o pontapé inicial para a institucionalização do movimento de base sob forma de um conselho coordenador em prol da legalização da cannabis (Coordinadora por la Legalización del Cannabis). Em maio de 2007, o movimento logrou mobilizar cerca de 10.000 pessoas em uma das maiores manifestaçóes desde a redemocratização, ocorrida em 1984. É importante salientar que os ativistas de forma alguma exigiam uma mudança completa na questão da política de drogas, mas sim, apenas uma nova forma de compreender o consumo da cannabis que, em sua perspectiva, não poderia estar no mesmo patamar que drogas mais fortes e mais prejudiciais à saúde como a pasta base de cocaína, comercializada na América Latina. Eles não defendiam, portanto, um novo paradigma para a política de drogas, mas sim, um re-framing no âmbito do discurso já existente, no qual a diferença entre drogas ilegais (aditivas e prejudiciais à saúde) e drogas legais como tabaco e álcool (em princípio menos prejudiciais à saúde) já estava estabelecida há muito tempo ${ }^{8}$. Eles se referiam à contradição em permitir o consumo e, ao mesmo tempo, por outro lado, proibir a produção e a comercialização da cannabis (HOFFMANN, 2020).

A coligação Frente Ampla, de centro-esquerda, no poder desde 2005, não havia, no entanto, dado passos concretos em direção a uma mudança na política de drogas. O presidente Tabaré Vásquez, um médico de carreira, posicionava-se de forma crítica

\footnotetext{
${ }^{7}$ Ver <http://cannabis.shoutwiki.com/wiki/Global_Marijuana_March>, Acesso em 8. nov. 2016.

8 Robert Entman define o conceito de framing da seguinte forma: "To frame is to select some aspects of a perceived reality and make them more salient in a communicating text, in such a way as to promote a particular problem definition, causal interpretation, moral evaluation, and/or treatment recommendation for the item described" (ENTMAN, 1993, p. 52, grifos no original).
} 
em relação à legalização ${ }^{9}$. A opinião pública também não apoiava, em grande parte, a legalização - predominava a percepçáo negativa da cannabis como uma droga imprevisível com potencial para abrir portas para outras drogas. No entanto, o tema teve um papel de proeminência nas campanhas eleitorais à presidência e ao parlamento, ocorridas em 2009. O sucessor de Vásquez, José Mujica, também pertencente à coligação Frente Amplio se mostraria mais aberto à ideia de liberalizaçáo. Era oriundo, no entanto, de uma geração mais antiga de ativistas políticos de esquerda, que não viam com bons olhos consumo de drogas. Ao contrário, enxergavam-no muito mais um empecilho para o desenvolvimento da consciência de classe. Após a troca de governo, não houve inicialmente iniciativa alguma em prol de alguma reforma. Dessa forma, não é possível considerar as eleiçóes do ano de 2009 e a sucessão presidencial como impulsos definidores para a mudança na política de drogas que viria a seguir.

Como real ponto de inflexão, Guzmán Castro (2014) identifica uma série de fatores ancorados na crise econômica do ano de 2002 quando o Uruguai terminou por ser afetado pela decretação da moratória argentina. Isso fez com que seu potencial econômico fosse abalado de forma severa e o percentual de pessoas vivendo em situaçáo de pobreza ultrapassasse os $30 \%$. Alguns efeitos da crise foram o aumento no consumo da fortemente viciante pasta base de cocaína e o aumento da criminalidade. A pasta base de cocaína era algo relativamente novo no Uruguai e causava grande insegurança na opiniáo pública. A taxa de assassinatos e a quantidade de assaltos reportados aumentou drasticamente entre 2002 e 2012 ainda que, na comparaçáo com outros países da regiáo, o Uruguai permanecesse sendo um dos países mais seguros. $\mathrm{O}$ problema da segurança pública, no entanto, passou a estar cada vez mais em foco na percepção pública quando a recuperaçáo econômica se tornou cada vez mais perceptível em 2004 e os problemas econômicos passaram a segundo plano. Em uma pesquisa do ano de 2012, 40\% dos entrevistados apontariam a segurança pública como maior problema a ser enfrentado (QUEIROLO; ROSSEL; ÁLVAREZ; REPETTO, 2019; RAMSEY, 2013).

Como as atividades do narcotráfico e da criminalidade associada à droga eram tidas como as causas da precariedade da segurança pública, a pressáo pública e a

\footnotetext{
${ }^{9}$ No ano de 2012, Vásquez se mostrava reticente em relação ao debate sobre a legalização: "[A maconha] não é uma droga leve. [...] O ideal seria não mexer com esse tipo de coisa", ver <http://www.subrayado. com.uy/Site/noticia/17035/nohayqueconsumirmarihuanadijotabarevazquezaliceales>. Acesso em 28. out. 2020.
} 
necessidade de uma açáo política à altura passaram a estar diretamente relacionadas à regulaçáo e à política de drogas. Isso ficou evidente quando o governo, em meados de 2012, após uma série de episódios de violência com grande repercussão, apresentou um pacote de medidas para a melhoria da situação da segurança pública (CASTRO, 2014). Além de penas mais duras para o tráfico de drogas, este pacote incluía um plano para a regulaçáo estatal do mercado da cannabis (HORTEUX; ROSSI-SCHMECHEL, 2015). Nele era possível identificar a lógica defendida por Batlle da política de drogas liberal e voltada para o mercado, que consistia em separar o mercado da cannabis da comercializaçáo ilegal de drogas mais pesadas e, assim, secar a fonte de recursos do comércio dessas últimas. $\mathrm{O}$ presidente Mujica apontou explicitamente para esse paradoxo - que o consumo legal da cannabis exigia uma forma ilegal de compra com todos os seus efeitos colaterais indesejáveis como o estabelecimento de um mercado ilegal (GARAT, 2015). Da mesma forma, uma mudança no contexto internacional deve ter tido um papel importante para que a legalização da cannabis, diferentemente do cenário em anos anteriores, passasse a integrar a agenda política do governo como parte de uma nova concepçáo de segurança pública. A liberalizaçáo do mercado de drogas nos estados norte-americanos do Colorado e Washington, que levou necessariamente a uma maior relutância dos Estados Unidos em relação a essa questão, também levou - bem como o apoio de defensores famosos da causa na América Latina - a que, nesse momento, se abrisse uma janela de oportunidade no âmbito internacional (HOFFMANN, 2016).

Além disso, o movimento de base pela legalização da cannabis também tinha ganho mais dinamismo. Isso desencadeou uma mudança de percepção: a cannabis passaria a ser tida como uma droga inofensiva quando comparada à pasta base de cocaína e seus consumidores já não eram mais considerados como grupo marginal, mas sim como cidadãs e cidadãos comuns, pertencentes à sociedade. Julio Calzada, responsável em grande medida pela elaboração da reforma pela JND, descreveria a canabis como 'democrática' na medida em que seria consumida por todas as camadas da sociedade igualmente, ao contrário da pasta base de cocaína, disseminada majoritariamente entre as camadas mais pobres da população (GARAT, 2015, p. 70). Essa percepção se tornou mais forte quando da detenção e prisão por vários meses de uma ativista de 68 anos por posse de uma grande quantidade de mudas de cannabis. Esse fato não apenas teve efeito mobilizador sobre o movimento pró-legalizaçáo, mas também fez parecer especialmente absurda a abordagem repressiva contra usuários da cannabis. A senhora descreveu o episódio posteriormente da seguinte forma: "Eles 
cercaram minha casa com cinco carros de polícia porque achavam que aqui encontrariam a versão feminina do Pablo Escobar" ${ }^{10}$.

A iniciativa decisiva do ponto de vista da política de drogas veio, no entanto, do governo, que agiu de forma independente e absolutamente inesperada aos olhos de observadores externos. Em relação às discussóes e contribuiçóes antes dessa iniciativa, é possível partir do pressuposto de que houve, de fato, um processo de aprendizagem. Dentre os membros do gabinete de Segurança, que elaborou as sugestóes supracitadas, estava também o Ministro da Defesa Eleuterio Fernández Huidobro que, por conta própria, havia se dedicado por muito tempo a abordagens alternativas para a política de drogas e que considerava a war on drugs uma estratégia fracassada (GARAT, 2015). Não seria, no entanto, acertado falar de um novo paradigma neste estágio uma vez que a proposta elaborada pelo governo inicialmente, com 15 medidas, definia apenas em uma delas um plano bastante vago para uma "legalizaçáo regulada e controlada" . ${ }^{11} \mathrm{~A}$ proposta, contudo, não apresentava uma abordagem bem alinhavada, mas já se diferenciava, ao menos das abordagens existentes. Em países como os Países Baixos ou a Espanha, apenas o consumo da cannabis permanecia isento de pena. Nos estados norte-americanos do Colorado e Washington a comercialização da cannabis estava em grande medida liberada, um modelo almejado pelo movimento pró-cannabis no Uruguai, modelo do qual o governo se distanciava explicitamente. Segundo essa perspectiva, a produção e distribuição da cannabis deveriam ocorrer sob controle estatal, ou seja, dentro da legalidade, porém sob enquadramento rigorosamente regulado. Não existiam, a essa altura, dados que comprovassem tal forma de abordagem, tampouco existiam projetos concretos que a embasassem. O próprio governo salientou que se tratava de um experimento: "Nós náo sabemos se essa abordagem será mais bem-sucedida, mas sabemos que o modelo que vigorou até agora [proibicionista] não funcionou" (GARAT, 2015, p. 66). O processo de aprendizagem de fato só ocorreu ao final da apresentação do plano de legalização ${ }^{12}$.

10 "Uruguay se abre a la marihuana", El País do dia 28.10.2012, Disponível em: <http://internacional.elpais.com/internacional/ 2012/10/26/actualidad/1351276832_100775.html> . Acesso em: 05. out. 2016.

11 "Estrategia por la vida y la convivencia", Disponível em: <https://medios.presidencia.gub.uy/ jm portal/2012/noticias/NO E582/Estrategia.pdf $>$. Acesso em: 6. nov. 2016.

12 "El Gobierno de Uruguay quiere asumir la venta de la marihuana”, El País do dia 21.6.2012, Disponível

em: 
Após o projeto ser encaminhado ao parlamento, uma nova dinâmica foi posta em marcha e a quantidade de envolvidos aumentou nitidamente. Se inicialmente falava-se tão somente do estabelecimento de um monopólio estatal relativa à produção e comercialização da cannabis, a lei terminou por conter um total de 44 artigos (CASTRO, 1992). Foi o resultado de um amplo debate ocorrido para além do parlamento, realizado amplamente na esfera pública, o que parecia indicar que haveria uma mudança de paradigma. Diversos especialistas internacionais foram consultados e o know how do movimento uruguaio pró-cannabis também foi levado em consideração na confecção da lei. Garat nota que, com o anúncio do debate em torno da lei, de certa forma um tabu se desfez e o tema da cannabis pôde ser discutido pela primeira vez de forma aberta e livre do estigma da ilegalidade (2015, p. 71). Um obstáculo, no entanto, era a própria opinião pública, que ainda permanecia marcada pela compreensão convencional acerca da droga. Pesquisas realizadas nos anos de 2012 e 2013 mostraram uma predisposição negativa por parte de mais de $60 \%$ dos entrevistados em relaçáo à intenção de legalizar a cannabis. Quando perguntados em pesquisa realizada em 2014 sobre onde os usuários deveriam obter a cannabis - se na farmácia ou com o narcotráfico - 78\% dos entrevistados, no entanto, apontaram a primeira opçáo (GARAT, 2015, p. $78)$.

Em julho de 2013, a lei foi finalmente aprovada pela Câmara dos Deputados e em dezembro de 2013 pelo Senado, em ambos os casos por maioria do partido da situação, o Frente Amplio. A lei previa quatro possibilidades: a cannabis para fins medicinais ficaria sob a responsabilidade do Ministério da Saúde; a produçáo para o consumo próprio era permitida, porém limitada a 6 mudas de planta por consumidor; nos clubes de cannabis, até 45 membros poderiam conjuntamente produzir maconha a partir do cultivo de até 99 mudas; e, finalmente, as farmácias poderiam vender até 40 gramas de cannabis por mês a usuários registrados, maiores de idade e residentes no Uruguai. A lei previa a criação de uma instituição que, entre outras atribuiçóes, faria o licenciamento dos produtores e manteria um inventário destes e também de usuários (ALBRECHT, 2014; HETZER; WALSH, 2016) ${ }^{13}$. Essa última regulação em especial

http://sociedad.elpais.com/sociedad/2012/06/21/actualidad/1340239024_658124.html, Acesso em: 6.out. 2020.

${ }^{13} \mathrm{Na}$ construção do inventário e da comercialização estatal houve algum atraso por conta de problemas técnicos até meados do ano de 2016, "Semana clave para la venta de marihuana en farmácias", EI Observador, 19.9.2016, ver <http://www.elobservador.com.uy/semana-clave-la-venta-marihuanafarmacias-n973351>. Acesso em: 28.out. 2020. 
foi mal recebida pelos ativistas pró-cannabis uruguaios, que tinham algumas reservas quanto ao registro de usuários. Com a legalização do autocultivo e dos clubes de cannabis, as suas demandas centrais estavam, no entanto, já contempladas (CASTRO, 2014).

A lei, sem dúvida, representou uma mudança substancial e também foi considerada internacionalmente como uma guinada em direção a uma solução alternativa, uma abordagem liberal à política de drogas (REPERGER, 2014). No entanto, teria isso significado que teria ocorrido uma mudança paradigmática nos termos de Hall? Com vistas à qualidade do conteúdo do debate bem como da trajetória da mudança política, é necessário levantar alguns pontos de questionamento. Do ponto de vista do conteúdo, o debate claramente foi extrapolando, ainda que de forma paulatina, fase após fase, a questão da cannabis e passando a tocar em questôes relacionadas aos direitos fundamentais e à questão das drogas de forma geral. No entanto, em sua maior parte, tratou-se de cotejar a cannabis frente a outras drogas, ou seja, uma questão ainda contida no interior do paradigma vigente. $\mathrm{O}$ governo de Mujica primou por deixar permanentemente claro que seu posicionamento fundamental acerca das drogas permanecia inalternado e que a legalização da cannabis seria apenas um mal necessário, uma medida para não deixar o terreno livre para os cartéis de drogas. Nesse contexto, náo é possível falar em uma mudança de paradigma na política de drogas. No Executivo não havia opinião predominantemente favorável à questão das drogas e a abordagem da securitização na política de drogas ainda era perceptível, ainda que tivesse como foco, naquele momento, a pasta base de cocaína e o crime organizado (CASTRO, 2014; HOFFMANN, 2020). Esse estado de coisas confirma o que afirmam os críticos de Hall: que paradigmas de políticas públicas raramente são completamente suplantados e que frequentemente não é possível distinguir dois paradigmas contrários de forma inequívoca (CARSTENSEN, 2015). Ao contrário, o caso do Uruguai evidencia que a mudança política acontece através de modificaçóes graduais de alguns instrumentos e elementos discursivos, com paradigmas distintos podendo coexistir ou se sobrepor.

A trajetória da mudança na política de drogas também não correspondeu ao padrão descrito por Hall. A opinião pública já estava participando desde relativamente cedo dos debates acerca do tema enquanto os atores estatais permaneciam ainda passivos. De fato, a iniciativa decisiva veio ao final conduzida pelo governo, mas os interesses vindos da sociedade, nesse caso do movimento da sociedade civil organizada 
pró-cannabis, tiveram um papel importante para que o tema viesse a pautar a agenda. O estopim concreto foi a situaçáo de segurança pública. Sua condição cada vez mais precária indiretamente terminaria por fazer com que o status da cannabis fosse reconsiderado. Isso se configurou menos como uma anomalia no contexto ao paradigma já existente e mais, de fato, como um aglomerado fortuito de discursos, situaçôes problemáticas e constelações político-partidárias como, por exemplo descritas pelo modelos dos múltiplos fluxos (KINGDON, 2014; HERWEG, 2013). O processo de aprendizagem no seio do governo aconteceu de fato em um período em que a decisão em relação a uma nova orientação na política de drogas já havia sido tomada. $\mathrm{O}$ governo não agiu com base em um sistema de convencimento coerente, mas sim sob a condição da insegurança e da contingência, o que corresponde mais ao modelo dos múltiplos fluxos que ao conceito proposto por Hall. Nesse sentido é compreensível que observadores e envolvidos afirmem ter havido uma mudança de paradigmas no Uruguai. No entanto, como categoria analítica, o referido conceito se mostrou apenas parcialmente aplicável ao caso.

Contudo, uma especificidade da política de drogas é que ela é influenciada pela esfera internacional de forma mais intensa que muitas outras áreas de política pública. Não apenas o discurso em torno da política de drogas possui um caráter transfronteiriço, mas também o enquadramento regulatório formal é regido por tratados internacionais. Uma mudança de paradigmas, fosse ela de fato constatada, deveria acontecer ao nível internacional. Portanto, se a legalização da cannabis no Uruguai não pode ser caracterizada como mudança de paradigmas, ela ainda assim pode ser compreendida como anomalia no interior do paradigma internacional de política de drogas. Uma anomalia que se move na direção de um enfraquecimento do discurso proibicionista contribuindo assim potencialmente para uma mudança mais ampla na política de drogas ${ }^{14}$.

\footnotetext{
${ }^{14}$ Uma tal possibilidade já era vislumbrada pelos parlamentares que aprovaram a referida lei. Um deles fez a seguinte ressalva: "This is an experiment without a doubt and it will have a demonstrable effect. That could be important for the world because it could be the start of a new paradigm" ("Uruguay's likely cannabis law could set tone for war on drugs in Latin America", The Guardian, 18.11.2013, ver <https:/www.theguardian.com/world/2013/nov/18/uruguay-cannabis-law-war-on-drugs-marijuana>. Acesso em: 14.nov.2016.
} 


\section{A virada da politica de drogas uruguaia no contexto internacional}

No contexto nível internacional, duas instâncias exercem influência sobre a política de drogas em países latinoamericanos. Por um lado, há as organizaçôes das Nações Unidas voltadas à política de drogas: a Comissão de Narcóticos (CND) como instância decisória, o Conselho Internacional para Controle de Narcóticos (INCB) como instância de controle bem como o Escritório das Naçóes Unidas sobre Drogas e Crime (UNODC) com sede em Viena. A base jurídica internacional da política de drogas das Nações Unidas, estabelecida pela Convenção Única do ano de 1961, complementada nos anos de 1971 e 1988, também enquadrava como ato criminoso a produção, comercialização e posse de substâncias definidas como especialmente prejudiciais à saúde. No artigo 3 da Convenção Contra o Tráfico Ilícito de Entorpecentes e Substâncias Psicotrópicas (UN Convention Against Illicit Traffic) do ano de 1988 lê-se que:

Each Party shall adopt such measures as may be necessary to establish as criminal offences under its domestic law, when committed intentionally: The production, manufacture, extraction; preparation, offering, offering for sale, distribution, sale, delivery on any terms whatsoever, brokerage, dispatch, dispatch in transit, transport, importation or exportation of any narcotic drug or any psychotropic substance [...]. The cultivation of opium poppy, coca bush or cannabis plant for the purpose of the production of narcotic drugs contrary to the provisions of the 1961 Convention and the 1961 Convention as amended (UNODC 2013, p. 127).

Ainda no ano de 1988, a Assembleia Geral das Naçóes Unidas formularia o objetivo de um mundo livre de drogas e uma notória redução na produção de drogas até o ano de 2008 (JELSMA; METAAL, 2004). A Assembleia Geral do ano seguinte, de 2009, reiterou a orientaçáo proibicionista, também apelidada de consenso de Viena, ainda que, quando da aprovação do novo plano de ação, perspectivas dissonantes estivessem cada vez mais evidentes (BEWLEY-TAYLOR, 2012).

A outra instância eram os Estados Unidos que, desde os anos de 1970, já incorporavam países produtores e países de passagem em sua estratégia nacional de combate às drogas, exportando assim a proclamada guerra às drogas (war on drugs) do presidente Nixon. Essa estratégia atingiu seu ápice com a invasão do Panamá em 
dezembro de 1989, que tinha como objetivo trazer à justiça o ditador Manuel Noriega, envolvido no comércio de drogas. Outras operaçóes de grande envergadura ocorreram na América Latina, no Peru em meados dos anos de 1980 e na Colômbia em meados dos anos de 1990, como parte de uma estratégia de contrainsurgência mais ampla que pretendia lograr a destruição das áreas de cultivo e das redes de produtores. ${ }^{15}$ Além disso, os Estados Unidos realizavam um monitoramento da política de drogas que resultava em sançóes caso fossem identificados quaisquer desvios em relação à conduta proibitiva: "Those countries that cooperate have been rewarded handsomely with economic assistance and trade benefits, while those that do not have faced sanctions and potentially the stigma of being labeled international pariah" (YOUNGERS, 2011, p. 11). Essa postura não sofreria alteração substancial com a eleição de Barack Obama apesar de um desarmamento retórico e do abandono das metáforas relacionadas à guerra. O paradigma proibicionista portanto ainda encontrava apoio no nível internacional tanto do ponto de vista institucional quanto do ponto de vista da política de poder, razão pela qual a chamada guerra às drogas (war on drugs) foi levada adiante apesar do seu claro fracasso ao longo de quatro décadas. Apenas nos anos mais recentes pareceu estar se desenhando uma mudança mais substancial.

Ao mesmo tempo, o paradigma proibicionista nunca esteve livre de contradiçôes e anomalias, sobretudo em relação à cannabis, que já desde o início dos anos de 1970 tinha um lugar cativo entre as subculturas ocidentais. O objetivo a ser alcançado, o da erradicação de todas as drogas, nunca pareceu ser realista. Além disso, os custos sociais, políticos e econômicos do combate às drogas pareciam cada vez mais evidentes. Sobretudo na América Latina, uma das maiores razôes para insatisfação era que, a aparente cura para o mal a ser combatido, ou seja, a guerra contra as drogas, parecia trazer mais problemas do que o próprio mal em si. Um ponto alto dessa mudança de discurso foi a publicaçáo, em 2009, do relatório "Drugs and Democracy: Toward a Paradigm Shift" da Latin American Commission on Drugs and Democracy, oriundo das iniciativas dos ex-presidentes Fernando Henrique Cardoso (Brasil), César Gaviria (Colômbia) e Ernesto Zedillo (México). Lê-se no relatório que: "Prohibitionist policies based on the eradication of production and on the disruption of drug flows as

${ }^{15}$ De acordo com Waltraud Queiser Morales (1989), a guerra às drogas (war on drugs) teve início na década de 1970 como estratégia de legitimação de política externa, em paralelo à construção da imagem do comunismo como inimigo, ao mesmo tempo em que se desenhava uma mudança na opinião pública. A importância do tema 'drogas' para a opinião pública dos anos de 1980 se refletia também na cultura popular, como por exemplo através da série de TV Miami Vice. 
well as on the criminalization of consumption have not yielded the expected results. We are farther than ever from the announced goal of eradicating drugs" ${ }^{16}$. A essa mesma conclusão também chegaria o relatório da OEA do ano de 2013, no qual as vantagens e as desvantagens das diferentes políticas de drogas haviam sido analisadas e no qual também se discutiam alternativas ao proibicionismo (BRIONES; CUMSILLE; HENAO; PARDO, 2013). Julio Calzada, da agência de drogas uruguaia, retomaria essa mesma argumentação para justificar a mudança na política de drogas no país: "We now have more consumers, bigger criminal organizations, money laundering, arms trafficking and collateral damage. As a control model, we are convinced that [the war on drugs] is more harmful than the drugs themselves" ${ }^{17}$. Um relatório da London School of Economics (2014) mostraria que os custos da chamada guerra às drogas recaíam sobretudo sobre os países mais pobres cujas estruturas estatais ainda por cima costumam ser mais vulneráveis: "Under the current prohibitionist approach to drug policy, producer and transit countries have ended up paying a very high cost in terms of violence, corruption and the loss of legitimacy of state institutions, among many others" (MEJIA; RESTREPO, 2014, p. 28). Frequentemente, nesse contexto, fazia-se a alusão à política fracassada de proibição de bebidas alcóolicas nos Estados Unidos nos anos de 1920 que, além de ter tido custos sociais e econômicos, também deu origem a organizaçóes criminosas que assumiram na sequência o tráfico de drogas (CHEPESIUK, 2002, p. xxi-xxiii).

Desde os anos 2000, as críticas ao paradigma vigente tornavam-se cada vez mais contundentes. Passaram a estar ligadas a demandas por uma redução de danos, em que se deslocasse o foco da política internacional de drogas de elementos como a criminalidade e a segurança para questóes relacionadas a políticas sociais e de saúde. Essas demandas também estavam sendo articuladas no interior da CND e levariam a conflitos com os defensores da abordagem proibicionista. Da mesma forma, ao nível da implementação, fissuras no consenso de Viena começaram a surgir, uma vez que cada vez mais Estados seguiam o exemplo dos Países Baixos descriminalizando o

16 "Drugs and Democracy: Toward a Paradigm Shift", Open Society Foundation. Disponível em: <https://www.opensocietyfoundations.org/sites/default/files/democracy_20090218.pdf>. Acesso em: 28.out. 2020.

17 “Uruguay's likely cannabis law could set tone for war on drugs in Latin America”, The Guardian, 18.11.2013. Disponível em: https://www.theguardian.com/world/2013/nov/18/uruguay-cannabis-lawwar-on-drugs-marijuana>. Acesso em: 28. out. 2020. 
consumo da cannabis. Essa política, no entanto, não emergiu diretamente da mudança de discurso descrita anteriormente, ao contrário: os países detentores de uma política de drogas liberal estavam na defensiva no interior da CND e tinham de se justificar por minar os esforços de redução da oferta por parte dos países produtores (BEWLEYTAYLOR, 2012). Enquanto a prática do consumo da cannabis sem penalização ainda era tolerada tacitamente, porque estava ao menos contida nas margens de interpretaçáo dos tratados, evidenciou-se no caso da Bolívia que o regime internacional demonstrava ser um fator limitante à política nacional de drogas. Por conta do forte significado da folha de coca para a cultura nacional e a ancoragem desta tradição na constituiçáo recém-promulgada em 2009 no país, a Bolívia solicitou que fosse feita uma exceção em relação ao consumo da folha de coca, mudança essa que teria exigido uma modificação formal do tratado. Um conjunto de Estados liderados pelos Estados Unidos se opôs a essa medida e o INCB acusou a Bolívia de comprometer com sua demanda o regime internacional de controle de drogas como um todo - fazendo com que a Bolívia saísse da Convençáo Única para Entorpecentes de $1961^{18}$. O INCB também reagiu de forma negativa às reformas levadas a cabo em estados federados dos Estados Unidos sem, no entanto, poder impedí-los de realizá-las ${ }^{19}$.

Diante desse panorama, a política de drogas uruguaia pode ser vislumbrada como tendo logrado um passo notável que, de fato, aponta para uma mudança política também ampla no nível internacional, uma vez que a lei de legalização de dezembro de 2013 estava em claro desacordo em relação a uma série de regulamentaçóes das convençóes internacionais sobre entorpecentes. O INCB havia emitido um alerta ao Uruguai já no ano de 2012 pois temia que sua decisão abrisse precedentes e tornasse o acordo difícil de ser mantido. O presidente do INCB, Raymond Yans, fez o seguinte alerta: "A chain is no stronger than its weakest link. If the chain of drug control is broken in one country or region [...] the entire international drug control system may be undermined" (BEWLEY-TAYLOR; BLICKMAN; JELSMA, 2014, p. 58). O governo uruguaio, no entanto, não se deixou impressionar e argumentou, por sua vez,

18 "UN Drug Board Attacks Bolivia: Drug Control Regime under Strain", WOLA, <https://www.wola.org/2012/02/ un-drug-board-attacks-bolivia-drug-control-regime-under-strain/>. Acesso em: 14. nov. 2016. No ano seguinte (2013) a Bolívia volta a fazer parte da Convenção Única, quando a exceção passa também a ser aceita.

19 "INCB President voices concern", Transnational Institute. Disponível em: <http://www.druglawreform.info/en/newsroom/ latest-news/item/4084-incb-president-voicesconcern-> . Acesso em: 14. nov. 2016. 
em favor da defesa dos direitos fundamentais: "[P] roduction and sale in the manner prescribed in the new law may be the best way, on the one hand, to combat drug trafficking, and on the other, to defend the constitutionally protected right to freedom of our fellow citizens" (Idem, p. 59). Em dezembro de 2013, imediatamente após a aprovaçáo da lei no Senado, o INCB acusou o Uruguai em um comunicado de imprensa de romper o tratado ${ }^{20}$. Ainda que essa reação fosse esperada e que não gerasse maiores consequências, a reação dos Estados Unidos teria grande peso e era difícil de ser antecipada. Em seu primeiro mandato, o presidente norte-americano Barack Obama ainda tinha insistido na linha proibicionista afirmando que a legalização não era uma soluçáo ao problema. O diretor do Office of National Drug Control Policy (ONDCP), Gil Kerlikowske, denominou a política de legalização como uma política "para inglês ver" ["bumper-sticker approach"] ${ }^{21}$. Contudo, diante das iniciativas cada vez mais numerosas em diversos estados dos Estados Unidos, o governo federal terminaria por iniciar uma mudança. O Ministério da Justiça aceitaria em agosto de 2013 a legalização da cannabis no Colorado e em Washington e o discurso oficial aderiria assim à questão dos custos sociais da criminalização da canabis. $\mathrm{O}$ presidente Barack Obama ainda se mostrava relutante, mas já não apresentava postura abertamente negativa ao caminho da legalização. Em entrevista ele afirmaria que: "I smoked pot as a kid, and I view it as a bad habit and a vice, not very different from the cigarettes that I smoked as a young person up through a big chunk of my adult life. I don't think it is more dangerous than alcohol" (REMNICK, 2014). Diante disso náo era possível aos Estados Unidos exercer pressão de forma plausível sobre o Uruguai. Assim, a embaixadora norte-americana no Uruguai sinalizaria que seu governo passava a compreender a reforma da lei de entorpecentes uruguaia como uma questáo interna ao país (WENNER; NADELMANN, 5 mar. 2014).

Diante da evolução apresentada, seria justificado falar em uma mudança de paradigmas na política de drogas em nível internacional? Teria sido o experimento

\footnotetext{
20 "Uruguay is breaking the International Conventions on Drug Control with the Cannabis Legislation approved by its Congress", United Nations Information Service, Disponível em: <http://www.incb.org/documents/Publications/PressRelease/PR2013/press_release_111213.pdf>. Acesso em: 28. out. 2020.

21 “Uruguay's marijuana experiment", LA Times, 21.8.2013. Disponível em: <http://articles. latimes.com/2013/aug/21/ opinion/la-oe-hakim-uruguay-legalizing-marijuana-20130821>. Acesso em: 15. nov. 2016.
} 
uruguaio de fato a peça de dominó tão temida pelo INCB, capaz de levar ao fim o velho paradigma proibicionista? Muitos observadores tinham a esperança de ver tal impacto e as reações na região mostraram que outros países também estariam prontos para trilhar o caminho uruguaio ${ }^{22}$. No entanto, o exemplo do Uruguai não fez escola até então. Uma razão para isso foi o início atrasado da instauração de um mercado regulado pelo Estado e também da venda da cannabis em farmácias, o que ainda se devia em larga medida à opiniáo pública em sua maioria avessa a isso. Assim, faltam dados empíricos acerca da factibilidade da iniciativa e também acerca das consequências da legalização sobre o consumo e o mercado ilegal de drogas (CHER, 21 mar. 2016). Além disso, muitos Estados evitam até hoje, baseados na possibilidade de haver dano à reputação, ferir de forma aberta as convençôes internacionais sobre entorpecentes. Seria necessária uma revisão radical da Convenção Única de 1961 para alavancar abordagens alternativas em relação à política de drogas no contexto internacional.

Tal passo era esperado por muitos observadores durante a sessão extraordinária sobre política de drogas na Assembleia Geral das Naçóes Unidas em abril de 2016. As esperanças foram, no entanto, frustradas: os tratados existentes não foram essencialmente alterados e a abordagem proibicionista foi mantida. Os Estados latinoamericanos tinham sido os que haviam se mobilizado de forma mais contundente em prol de uma reforma ampla, mas não puderam fazer valer sua decisão frente aos defensores do status quo ${ }^{23}$. A mudança paradigmática ao nível internacional teve, portanto, de ser adiada. Uma mudança a médio prazo dependerá do sucesso do experimento uruguaio na área da política de drogas, cujo concretização ainda não é possível vislumbrar ${ }^{24}$.

\section{Considerações finais}

A opção uruguaia por trilhar um novo caminho na política de drogas marcou um momento histórico não apenas para o próprio país, como para o regime

\footnotetext{
22 “Uruguay's neighbors now considering legalization of pot”, PRI.org, 24.12.2013, Disponível em: http://www.pri.org/stories/ 2013-12-24/uruguays-neighbors-now-considering-legalization-pot . Acesso em: 15 . nov. 2016.

23 "UN backs prohibitionist drug policies despite call for more 'humane solution", The Guardian, 20.4.2016. Disponível em: <https://www.theguardian.com/world/2016/apr/19/unsummitglobalwardrugsagreementapproved>. Acesso em: 15.nov. 2016.

${ }^{24}$ Para um balanço preliminar da experiência, ver Ella Jordan (2018).
} 
internacional de política de drogas como um todo. Pela primeira vez um país assumiu posição distinta da linha proibicionista, que havia sido estabelecida nos tratados internacionais desde 1961. Por isso, muitos observadores falavam de uma mudança de paradigma, o que diante do significado e do efeito sinalizador desse passo certamente parecia justificado. No entanto, no sentido mais estrito descrito por Peter Hall, essa avaliação não se sustenta. $\mathrm{O}$ processo decisório no Uruguai divergiu em vários pontos da sequência com base na qual Hall desenvolveu estudo sobre a mudança na política econômica do Reino Unido ao final dos anos de 1970. Ao nível do conteúdo, vimos que a mudança política se deu apenas frente à cannabis, enquanto elementos centrais do paradigma proibicionista em relação a outras drogas se mantiveram inalterados.

Tampouco no contexto internacional deu-se uma mudança política a partir da decisão tomada pelo Uruguai. Ao contrário, o paradigma existente foi endossado em abril de 2016 pela Assembleia Geral das Naçóes Unidas. Um processo de aprendizagem, tal qual seria de se esperar conforme a ideia de Hall, não pôde ser detectado nas autoridades institucionais do paradigma vigente. Ao contrário, as instâncias das Naçôes Unidas voltadas à política de drogas posicionaram-se como baluartes da manutenção do status quo. A pressão foi exercida de fora para dentro, através de um movimento pró-legalização da cannabis, e também pelos seus apoiadores em cada país, sobretudo na América Latina. Essa constelação corresponde à abordagem pluralista clássica, distinta da posição defendida por Hall: os interesses são organizados ao nível da sociedade e são articulados em relação às instâncias decisórias estatais - nesse caso, as instâncias internacionais. Se de fato uma mudança no regime internacional de controle de drogas tivesse ocorrido, ela teria sido o resultado de uma modificação ao nível do discurso e das relaçóes de poder entre os atores envolvidos, completamente consoante ao modelo pluralista do processo político. Um processo de aprendizagem em nível institucional, como suposto por Hall como fator decisivo para a mudança, não parece ser visível nesse caso.

Thomas Kestler é Pesquisador do Instituto de Ciência Política e Sociologia da Universidade de Würzburg. E-mail: thomas.kestler@uni-wuerzburg.de. 


\section{Referências}

ALBRECHT, Luke. Uruguay's Drug Policy Reform: at the Cutting Edge of Alternative Policy. Journal of Peace and Conflict Studies, v. 1, n. 1, 2014, p. 39-49.

BÉLAND, Daniel. Ideas and Institutions in Social Policy Research. Social Policy and Administration, v. 50, n. 6,2016, p. 734-750.

BÉLAND, Daniel. Ideas and Social Policy: An Institutionalist Perspective. Social Policy and Administration, v. 39, n. 1, 2005, p. 1-18, 2005.

BEWLEY-TAYLOR, David R. International Drug Control: Consensus Fractured. Cambridge: Cambridge Univ. Press, 2012.

BEWLEY-TAYLOR, David R.; BLICKMAN, Tom; JELSMA, Martin. The Rise and Decline of Cannabis Prohibition. Transnational Institute, 2014. Disponível em: <https://www.tni.org/files/download/rise_and_decline_web.pdf>. Acesso em: 14 nov. 2016.

BLYTH, Mark. Structures Do Not Come With Instruction Sheets: Interests, Ideas and Progress in Political Science. Perspectives on Politics, v. 1, n. 4, 2003, p. 695-706.

BRIONES, Alvaro; CUMSILLE, Francisco; HENAO, Adriana; PARDO, Bryce. The Drug Problem in the Americas. Washington, D.C.: OAS, 2013. (OAS official records). Disponível em: <http://www.oas.org/documents/eng/press/Introduction_and_Analytical_Report.pdf>, Acesso: [s/d].

CARSTENSEN, Martin B. Bringing Ideational Power into the Paradigm Approach: Critical Perspectives on Policy Paradigms in Theory and Practice. In: HOGAN, J.; HOWLETT, M. (Org.). Policy paradigms in Theory and Practice: Discourses, Ideas and Anomalies in Public Policy Dynamics, New York: Palgrave Macmillan, 2015, p. 295-318.

CASTRO, Guzmán. Institutional Change, Ideas, and Political Coalitions: The Case of Marijuana Regulation in Uruguay. APSA, Washington, D.C, 2014. (110 ${ }^{\text {th }}$ Annual Meeting, 28.-31.8.2014). Disponível em: <http://aucip.org.uy/docs/v_congreso/ArticulospresentadosenVcongresoAucip/AT21-

PoliticasPublicas/GuzmanCastro_FromPunishment.pdf>. Acesso em: 8 nov. 2016.

CHEPESIUK, Ron. The War on Drugs: An International Encyclopedia. Santa Barbara: ABC-CLIO, 2002. Disponível em: <http://gbv.eblib.com/patron/FullRecord.aspx?p=265376>. Acesso em: [s/d].

CHER, Ladan. Uruguay's Half-Baked Marijuana Experiment. Foreign Policy, 21 mar. 2016. Disponível em: <https://foreignpolicy.com/2016/03/21/uruguay-marijuana-legalization/>, Acesso em: 28 out. 2020 .

ENTMAN, Robert M. Framing: Toward Clarification of a Fractured Paradigm. Journal of Communication, v. 43, n. 4, 1993, p. 51-58.

EVANS, Peter B.; RUESCHEMEYER, Dietrich; SKOCPOL, Theda (Ed.). Bringing the State Back In. Cambridge: Cambridge Univ. Press, 1985.

GARAT, Guillermo. El camino: Cómo se reguló el cannabis en Uruguay según sus actores políticos y sociales 2014. Montevideo: Junta Nacional de Drogas [u.a.], 2015.

GARIBOTTO, Giorgina. Cárceles y drogas en Uruguay. In: BOITEUX, L.; CORDA, A.; EDWARDS, S. (Org.). Sistemas sobrecargados: Leyes de drogas y cárceles en América Latina, Ámsterdam, Washington, D.C.: TNI; WOLA, 2010, p. 82-89. 
HAJER, Maarten A. Discourse Coalitions and the Institutionalization of Practice: The Case of Acid Rain in Britain. In: FISCHER, F.; FORESTER, J. (Org.). The Argumentative Turn in Policy Analysis and Planning, Durham, N.C: Duke Univ. Press, 1993, p. 43-76.

HALL, Peter A. Policy Paradigms, Social Learning, and the State: The Case of Economic Policymaking in Britain. Comparative Politics, v. 25, n. 3, 1993, p. 275-296.

HALL, Peter A. (Ed.). The Political Power of Economic Ideas: Keynesianism Across Nations. Princeton, NJ: Princeton Univ. Press, 1989.

HERWEG, Nicole. Der Multiple-Streams-Ansatz - ein Ansatz, dessen Zeit gekommen ist? Zeitschrift für Vergleichende Politikwissenschaft, v. 7, n. 4, 2013, p. 321-345.

HETZER, Hannah; WALSH, John. Pioneering Cannabis Regulation in Uruguay. NACLA Report on the Americas, v. 47, n. 2, 2016, p. 33-35, 2016.

HOFFMANN, Jonas von. "Someone Has To Be the First": Tracing Uruguay's Marijuana Legalisation Through Counterfactuals. Journal of Politics in Latin America, v. 12, n. 2, 2020, p. 177-199, 2020.

HOFFMANN, Jonas von. The International Dimension of Drug Policy Reform in Uruguay. The International Journal on Drug Policy, v. 34, 2016, p. 27-33, 2016.

HORTEUX, Christoph; ROSSI-SCHMECHEL, Felipe. Ein Fall von Entsicherheitlichung? Die Regulierung von Cannabis in Uruguay, Institut für Politikwissenschaft an der Philipps UniversitätMarburg (Working Paper 9), 2015.

JELSMA, Martin; METAAL, Pien. Cracks in the Vienna Consensus: The UN Drug Control Debate. WOLA Drug War Monitor, jan., 2004, p. 1-22.

JORDAN, Ella. Marijuana Legalization in Uruguay. Centre for Public Impact, 2015. Disponível em: <https://www.centreforpublicimpact.org/case-study/marijuana-legalisation-in-uruguay/>. Acesso em: 28 out. 2020.

KINGDON, John W. Agendas, Alternatives, and Public Policies. 2. ed. Boston: Pearson Education, 2014.

KUHN, Thomas S. The Structure of Scientific Revolutions. 3. ed. Chicago: Univ. of Chicago Press, 2009, 212 p.

MEJIA, Daniel; RESTREPO, Pascual. Why Is Strict Prohibition Collapsing? A Perspective from Producer and Transit Countries. In: LSE [London School of Economics and Political Science] (Org.). Ending the Drug Wars (Report of the LSE Expert Group on the Economics of Drug Policy), Londres, 2014, p. 26-32.

QUEIROLO, Rosario; ROSSEL, Cecilia; ÁLVAREZ, Eliana; REPETTO, Lorena. Why Uruguay Legalized Marijuana? The Open Window of Public Insecurity. Addiction, v. 114, n. 7, 2019, p. 13131321.

QUEISER MORALES, Waltraud. The War on Drugs: A New US National Security Doctrine? Third World Quarterly, v. 11, n. 3, 1989, p. 147-169.

RAMSEY, Geoffrey. Uruguay: Marijuana, Organized Crime and the Politics of Drugs. Disponível em: <http://www.insightcrime.org/images/PDFs/2016/uruguay_legalization.pdf>. Acesso em: 15 nov. 2016.

REMNICK, David. Going the Distance: On and Off the Road with Barack Obama. In Sight. Organized Crime in the Americas, 2013. Disponível em: 
<http://www.newyorker.com/magazine/2014/01/27/going-the-distance-david-remnick>. Acesso em: 15 nov. 2016.

REPERGER, Simone. Neue Wege in der Drogenpolitik: Das Laboratorium Uruguay. Berlin: FriedrichEbert-Stiftung Referat Lateinamerika und Karibik, 2014. Disponível em: <http://library.fes.de/pdffiles/iez/10950.pdf>. Acesso em: 6 nov. 2016.

SANJURJO GARCÍA, Diego. El cambio en las políticas de estupefacientes: el ejemplo de Uruguay. Revista Jurídica, v. 27, 2013, p. 291-311.

UNODC [UNITED NATIONS OFFICE ON DRUGS AND CRIME]. The International Drug Control Conventions. New York: United Nations, 2013.

WENNER, Jann S.; NADELMANN, Ethan. Obama's Pot Breakthrough. Rolling Stone, 5 mar. 2014. Disponível em: <https://www.rollingstone.com/politics/politics-news/obamas-pot-breakthrough99944/>. Acesso em: 28 out. 2020.

YOUNGERS, Coletta A. Drug Control Policy: What the United States Can Learn from Latin America. LASA Forum, v. 42, n. 2, 2011, p. 11-13.

Texto recebido em 03 de fevereiro de 2021. Aprovado em 14 de abril de 2021. 